
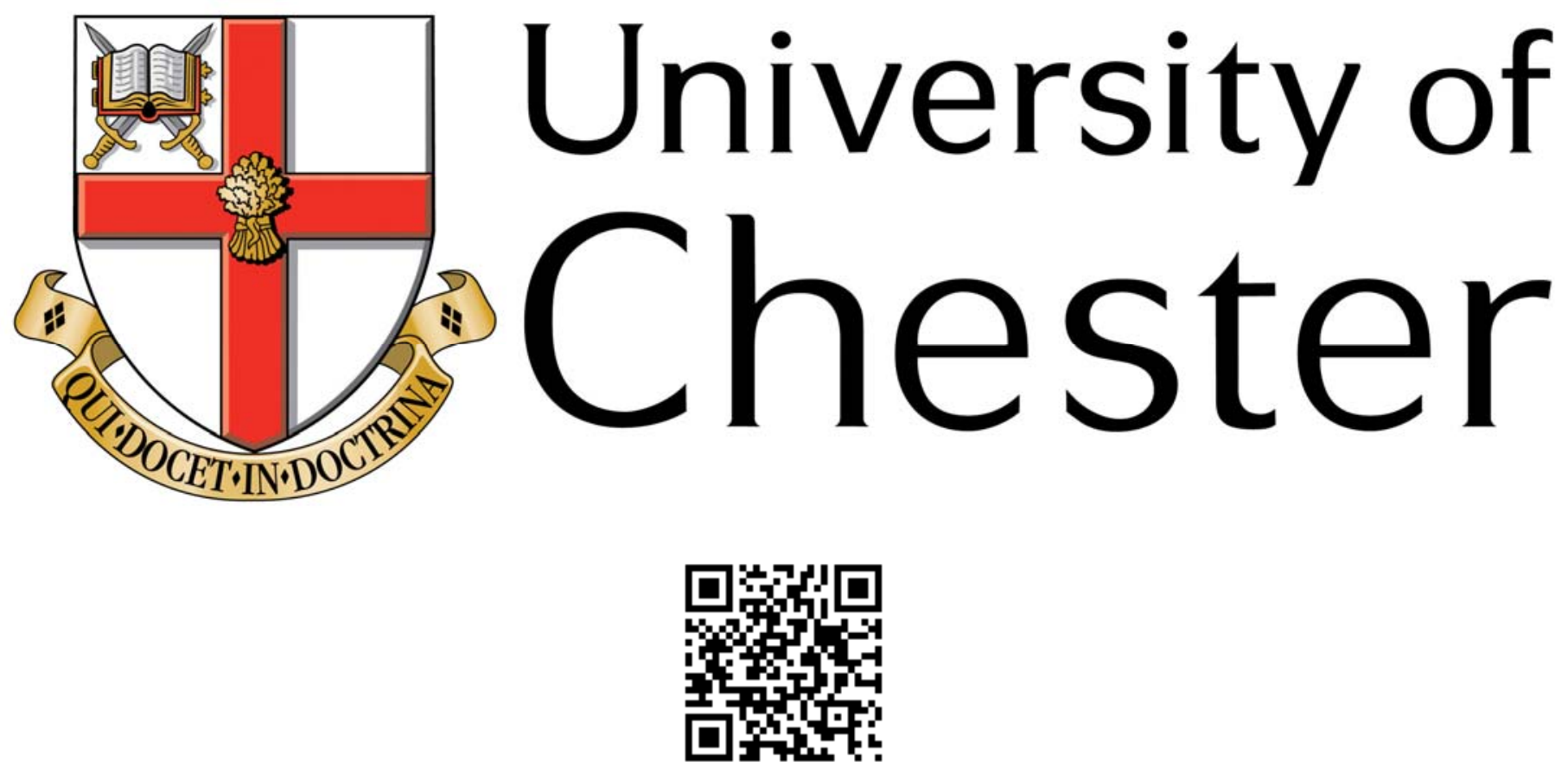

This work has been submitted to ChesterRep - the University of Chester's online research repository

\title{
http://chesterrep.openrepository.com
}

Author(s): Robert E G Smith ; Trevor J Davies ; Nicholas de B Baynes ; Richard J Nichols

Title: The electrochemical characterisation of graphite felts

Date: 2015. Appeared online 25 March 2015

Originally published in: Journal of Electroanalytical Chemistry

Example citation: Smith, R. E. G., Davies, T. J., Baynes, N. de B., Nichols, R. J. (2015). The electrochemical characterisation of graphite felts. Journal of Electroanalytical Chemistry, 747, 9-38.

http://dx.doi.org/10.1016/j.jelechem.2015.03.029

Version of item: Authors' accepted manuscript

Available at: http://hdl.handle.net/10034/550052 


\section{The Electrochemical Characterisation of Graphite Felts}

Robert E. G. Smith, ${ }^{a}$ Trevor J. Davies, ${ }^{b, c}{ }^{*}$ Nicholas de B. Baynes, ${ }^{c}$ and Richard J. Nichols. ${ }^{a}$

a. Department of Chemistry, University of Liverpool, Crown Street, Liverpool, UK, L69 7ZD.

b. Department of Natural Sciences, University of Chester, Thornton Science Park, Pool Lane, Ince, Cheshire, UK, $\mathrm{CH} 2$ 4NU.

c. ACAL Energy Limited, The Heath Business and Technical Park, Cheshire, UK, WA7 4QX

To be submitted to the Journal of Electroanalytical Chemistry.

${ }^{*}$ Author to whom all correspondence should be addressed

Email: t.davies@chester.ac.uk

Tel.: +44(0)1244 512297 


\begin{abstract}
With the increasing demand for advanced energy storage, redox flow batteries (RFBs) are a rapidly growing market and research area. Carbon fibre based materials like graphite felts (GFs) are commonly used in RFBs as electrodes due to their electrochemical activity, high permeability for liquids, high surface area and relatively low cost. Previous characterisation of GFs has involved flow systems, which can be complicated to replicate and expensive. Using pre-treatment techniques to ensure sufficient wetting, GFs can be used effectively in quiescent electrochemistry. By combining the experimental voltammograms with digital simulations, key properties such as capacitance, electrode kinetics, average pore size and electrochemical surface area can be determined. This allows for the rapid and low cost examination of multiple GFs and pre-treatment methods, providing a useful tool for RFB development. In addition, the GF electrodes used in the study show promising limit of detection values, with initial experiments suggesting these electrodes may have applications in electroanalysis.
\end{abstract}

\title{
Key Words
}

Graphite felt; electrode; carbon electrochemistry; cyclic voltammetry;

\section{Highlights}

- A new method is reported for the electrochemical characterization of graphite felts

- The method combines cyclic voltammetry experiments with simulations

- Surface area, average pore size, capacitance and reactivity are determined

- The method can be applied to other porous electrodes

- The graphite felt electrodes appear to have low limits of detection 


\section{Introduction}

Graphite felts (GFs) are the electrode material of choice for redox flow batteries (RFBs) [1-4]. These materials remain more popular than other carbon based materials, such as carbon paper, a result of their favourable liquid permeability and high surface area [5-6]. Due to the popularity of these materials and the rapidly growing RFB market, a large amount of research has been conducted on their physical and electrochemical properties, where the main objective is to improve cell performance, i.e. obtain higher current densities whilst maintaining the required operating efficiency. A common objective of GF research has been the measurement of mass transport coefficients in miniaturized flow cells [7-9]. Although these experiments provide useful property data, they can be difficult to set up and require specialized/bespoke equipment. In an attempt to simplify experimental requirements, some researchers have made stationary electrodes from graphite felts and studied the material with classical 3 electrode cyclic voltammetry [10-12]. However, as Figure 1 shows, many GFs are hydrophobic and difficult to wet. The apparent high contact angle suggests a quasi-super-hydrophobic surface, similar to that reported by Banks et al. for graphene foam [13]. As a result, the amount of the interior surface in contact with electrolyte is difficult to control and can generate misleading results, especially if electrodes of different surface wettability are being compared.

This paper reports the development of an elegant technique that allows GFs to be used as electrodes in quiescent voltammetry experiments. This involves a felt pre-treatment to allow for homogeneous wetting through the GF sample, followed by cyclic voltammetry in a redox system of interest. Using simple voltammetric techniques combined with a commercially available simulation package, key properties such as capacitance, electrode kinetics, average pore size and electrochemical surface area can be determined. This is of particular interest for examining multiple or modified GFs quickly, without the need for a complicated experimental set up. The developments reported in this paper pave the way for the rapid screening of electrode materials and electrode treatments for redox flow batteries and other applications. Furthermore, the GF electrodes used in this study show promising voltammetry at very low concentrations of redox species suggesting possible applications in electroanalysis.

\section{Experimental Methods}

All chemicals were used as received from Sigma Aldrich without further purification unless stated otherwise. Solutions of ferricyanide with $\mathrm{KNO}_{3}$ supporting electrolyte, ferrocyanide with $\mathrm{KCl}$ supporting electrolyte and vanadium(V)oxide in sulphuric acid were prepared using ultrapure water (18 $\mathrm{M} \Omega \mathrm{cm}^{-1}$, Milli- $\left.{ }^{\circledR}\right)$. Non-aqueous solutions of ferrocene with tetrabutylammonium perchlorate (TBAP) in acetonitrile were also prepared. Two potentiostats were used for electrochemical experimentation, a Metrohm Autolab PGSTAT $128 \mathrm{~N}$ potentiostat and a $\mathrm{CH}$ Instruments $1100 \mathrm{~B}$ potentiostat. Solution resistance was measured and compensated for via an in-built method on the $\mathrm{CH}$ instruments potentiostat and a manual, stepped-increase method on the Autolab potentiostat.

A standard three electrode configuration was employed for all electrochemical measurements. Three $3 \mathrm{~mm}$ diameter carbon electrodes (IJ Cambria Scientific Ltd); edge plane pyrolytic graphite (EPPG), basal plane pyrolytic graphite (BPPG) and plastic formed carbon (PFC), were used to determine electrochemical parameters of the electrolyte solutions. The BPPG electrode was 
prepared by polishing the electrode with a $1 \mu \mathrm{m}$ polycrystalline diamond suspension (Buehler) on a silk-type cloth pad (Kemet International) before washing the surface in ultrapure water and briefly sonicating. The electrode surface was then refreshed by removing excess graphite with sellotape. This was repeated multiple times before washing the electrode in acetone to remove any residue. The PFC and EPPG electrodes were prepared by polishing with diamond slurries of decreasing particle size $(9 \mu \mathrm{m}, 3 \mu \mathrm{m}$ and $1 \mu \mathrm{m})$ on a silk-type cloth pad before washing the surface in ultrapure water and briefly sonicating. A bright platinum wire with attached platinum wire mesh (Metrohm UK) was used as the counter electrode and a saturated calomel electrode (IJ Cambria Scientific Ltd) was used as the reference. In non-aqueous solutions a double junction (IJ Cambria Scientific Ltd) was used to reduce contamination of the reference.

The GF used was GFD 2.5, a commercially available felt supplied by SGL Group, with a nominal thickness of $2.8 \mathrm{~mm}$ (measured under a slight compressive force) [14]. A $1 \mathrm{~cm}^{2}$ piece of GF was cut from a clean roll of the felt using a bespoke 'cookie cutter' tool. After weighing the GF using a 4 point balance (Sartorius, TE214S), a $0.5 \mathrm{~mm}$ (diameter) platinum wire 'fish hook' was passed through the felt to secure it and provide a good electrical connection to the whole of the felt piece. This is shown in the photographs in Figure 2. In all of the redox solutions, cyclic voltammetry was also conducted with the bare platinum fish hook submerged in solution. The size of the voltammetric signal from the platinum wire fish hook was negligible compared to the signal from the GF electrode.

Due to the hydrophobic nature of the carbon fibre surfaces and the small average pore size of the felt, it was very difficult to remove all the trapped air from within the felt using only aqueous solutions (this was necessary to make sure all the electrode surface was in contact with the electrolyte). Consequently, for measurements in aqueous solutions an electrode wetting procedure was developed. The GF electrode was initially washed in ethanol before being rinsed with ultrapure water. It was then agitated in a sacrificial sample of the electrochemical solution before being transferred to the electrochemical cell. This ensured full wetting of the interior surface of the GF with the redox solution under investigation. Other methods of electrode wetting were investigated. These included sonication in the aqueous electrolyte, the use of a bespoke flow cell and washing with the aqueous electrolyte (with a laboratory wash bottle). However, it was found that without an initial wash in a non-aqueous solvent it was very difficult to remove all the trapped air from within the felt, which lead to reduced voltammetric signals and poor repeatability. A pre-wash with a water miscible non-aqueous solvent (i.e. ethanol or acetone) was found to be the best method for removing the trapped air within the felt (before performing experiments with an aqueous electrolyte). In non-aqueous solutions the ethanol pre-washing step was not required and the GF was simply agitated in a sacrificial sample of the electrochemical solution before immersion into the redox solution.

The large surface area of the GF electrodes ( $60 \mathrm{~cm}^{2}$ per electrode) resulted in currents of magnitude $\sim 10 \mathrm{~mA}$ when solutions of $\mathrm{mM}$ concentrations of redox species were used. This caused distortions in the voltammetry due to uncompensated solution resistance. Two methods were used to correct for this. In some cases the "IR-compensation" feature in the potentiostat was used to automatically compensate the potential signal for solution resistance (where $I$ is the current and $R$ is the solution resistance between the reference and working electrodes). In other cases the concentration of redox species was reduced 10-100 times to decrease the current magnitude and 
eliminate the requirement for $I R$-compensation (i.e. the value of $I R$ became insignificant). More details are given in the Supporting Information.

The electrochemical simulation software employed was DigiElch (v7.FD) from ElchSoft, Germany. SEM (Quanta 250 FEG, FEI) was used to determine the diameter of the fibres within the carbon felt. The fibres were found to have an average diameter of $8 \mu \mathrm{m}$ from a range of measurements. Typical SEM images are shown in Figure 3 for a range of magnifications.

The "smooth" surface area of the felt can be estimated by approximating the felt as one cylindrical carbon fibre. The mass of the felt electrode, $m$, can be used to determine the total volume of the carbon fibres, $V_{\mathrm{cf}}$, via the simple density relationship:

$$
V_{\mathrm{cf}}=\frac{m}{\rho_{\mathrm{cf}}}
$$

Where $\rho_{\mathrm{cf}}$ is the density of carbon fibres and is generally considered to be around $1.8 \mathrm{~g} \mathrm{~cm}^{-3}$ [15]. The equivalent length of the carbon fibre, $L_{\mathrm{cf}}$, is then deduced using the equation for the volume of a cylinder:

$$
\pi r^{2} L_{\mathrm{cf}}=V_{\mathrm{cf}}
$$

Where $r$ is the radius of the carbon fibres in the felt, determined to be $4 \mu \mathrm{m}$ for the particular felt used in this investigation. The surface area of the fibre (and hence the whole electrode), $A_{c f}$, is then determined using:

$$
A_{\mathrm{cf}}=2 \pi r L_{\mathrm{cf}}
$$

The average pore size within the felt proved to be a difficult quantity to measure. Initially, fifty SEM images were analysed using the method reported for carbon fibre papers in [16]. Unfortunately, the 3-dimensional structure of the GF samples resulted in meaningless results from the image analysis (the method works well for carbon papers, which are considered to possess a 2-dimensional structure). Mercury porosimetry and BET were also unable to give meaningful pore size distribution data for this material. Therefore, a conceptual approach to estimate the average pore radius was developed.

The square unit cell model in figure 4(a) represents an idealized view of the GF structure and provides an estimation of the average distance between fibres, which can be used to approximate the average pore size. For the cubic unit cell to be representative of the material, the area of the empty space, divided by the area of the unit cell should equal the porosity, of the felt, $\phi$ :

$$
\phi=1-\left(\frac{\pi r^{2}}{x^{2}}\right)
$$

Where $x$ is the dimension of the unit cell, as labelled in Figure 4. The porosity of the felt can be determined using the total volume of the felt, $V_{\text {Tot }}$, and the equation:

$$
\phi=1-\left(\frac{m}{V_{\text {Tot }} \rho_{\mathrm{cf}}}\right)
$$

The shortest fibre surface to fibre surface distance, $d$, is then simply given by: 


$$
d=x-2 r=\sqrt{\left[\frac{\pi r^{2} V_{\mathrm{Tot}} \rho_{\mathrm{cf}}}{m}\right]}-2 r
$$

where the parameters $r, m, V_{\text {Tot }}$ and $\rho_{\mathrm{cf}}$ are all known.

In terms of evaluating a pore radius, $R_{p}$, to compare with experimental results and subsequent model, an approximation is shown in Figure 4 (b), where four unit cells are drawn together. In this case, $R_{p}$ resembles the pore radius and is given by:

$$
R_{p}=\left(\frac{x}{\sqrt{2}}\right)-r=\sqrt{\left(\left[\frac{\pi r^{2} V_{\mathrm{Tot}} \rho_{\mathrm{cf}}}{m}\right] / 2\right)}-r
$$

In the case of a hexagonally packed unit cell, the equation for $R_{p}$ is also given by equation 7 .

\section{Simulations}

Simulations were used in combination with experimental GF voltammograms to extract electrochemical and physical properties of the GF electrodes. The following section describes the model used to simulate the cyclic voltammetry of GF (and other porous) electrodes.

Consider the schematic diagram in Figure 5. The porous GF electrode can be approximated as an ensemble of pores that mimic tube electrodes, with the interior surface being the active area. Each pore of radius $R_{p}$ and length $L$ can be approximated as two parallel plate electrodes separated by a distance $2 R_{p}$ where the area of each plate is $\pi\left(2 R_{p}\right) L / 2$. Note that for planar diffusion where the pore radius is comfortably greater than the diffusion layer thickness, the voltammetric response of the tube and parallel plates should be the same (assuming planar diffusion). However, as $R_{p}$ becomes similar to the diffusion layer thickness and the depletion zone extends into the pore, the voltammetric signals for the two electrodes will start to differ as the parallel plates have an enclosed electrolyte volume of $\pi\left(2 R_{p}\right)^{2} L / 2$, whereas the tube has an enclosed electrolyte volume of $\pi\left(2 R_{p}\right)^{2} L / 4$. This represents a source of error in the simulation approach but is acceptable as a first attempt, allowing the use of commercially available cyclic voltammetry software. Due to a region of zero flux between the parallel electrodes in Figure 5, the situation can be considered as, and is mathematically identical to, the situation where an insulating plate is placed above an electrode at a height of $R_{p}$ [17]. In this situation the total area of the parallel plate electrodes is equal to the area of the single plate electrode in the plate-insulator model. The cyclic voltammetry of the latter can be simulated with commercially available software, such as DigiElch or DigiSim [18], using the finite diffusion package intended for thin layer voltammetry [19]. In the final step of the model, the whole porous electrode is approximated as a plate electrode, separated from an insulating plate by a distance of $R_{p}$.

In the following description, the redox system is a simple one electron reduction of species A to B:

$$
\mathrm{A}+e^{-} \rightarrow \mathrm{B}
$$


Where the initial concentration of $A,[A]$, is $1 \mathrm{mM}$, initial $[B]$ is $0 \mathrm{mM}$, the formal potential, $E_{\mathrm{f}}$, is $0 \mathrm{~V}$, the diffusion coefficients of $A$ and $B, D$, are equal to $1 \times 10^{-6} \mathrm{~cm}^{2} \mathrm{~s}^{-1}$ and the electrode rate constant, $k^{\ominus}$, is $0.01 \mathrm{~cm} \mathrm{~s}^{-1}$. The value of $D$ can be obtained via separate experiments with traditional macroelectrodes, whereas $k^{\ominus}$ can be initially estimated then refined once conditions of semi-infinite diffusion are known (see later).

The objective of the simulation method is to determine the two unknowns of electrochemical surface area and average pore size from the experimental cyclic voltammetry response of the porous electrode. Consider the example where the porous electrode can be described as the plate electrode in Figure 5 with a surface area of $10 \mathrm{~cm}^{2}$ and a pore radius, $R_{p}$, of $30 \mu \mathrm{m}$. Figure 6 illustrates cyclic voltammograms (simulated) for the electrode in the given redox solution at scan rates of $0.01,0.1$ and $1 \mathrm{~V} \mathrm{~s}^{-1}$. At low scan rates, thin layer voltammetry is observed, with well-defined forward and reverse peaks with almost identical peak potentials [19]. As the scan rate increases, the mass transport changes to semi-infinite diffusion and "classically shaped" voltammograms are observed. The transition from thin layer to semi-infinite diffusion voltammetry can be seen in plots of cathodic peak current, $I_{p}^{c}$ vs. scan rate, $v$, and $I_{p}^{c}$ vs. $v^{0.5}$ (see the Supporting Information). The changing shape of the voltammograms and $I_{p}{ }^{c}-v$ relationship is predominantly affected by diffusion layer overlap. At low scan rates, the diffusion layer thickness is larger than $R_{p}$, leading to heavily overlapping diffusion layers within the pore and consequently thin layer voltammetry. At the highest scan rates the diffusion layer is comfortably smaller than $R_{p}$ leading to little or no diffusion layer overlap and voltammetry where mass transport is described by semi-infinite diffusion. Compton and co-workers have previously shown diffusion layer overlap can be used to determine the size of individual electrodes in microelectrode arrays and the size of blocking particles on electrode surfaces [20-24]. Using the same principle, diffusion layer overlap can be used to determine the size of pores in porous electrodes. A direct method is to compare simulated voltammograms with experimental voltammograms and vary the parameters to find the best fit. However, a more elegant and relatively faster method is now described.

Imagine the voltammograms in Figure 6 are actually real experimental voltammograms for a GF electrode of unknown surface area and average pore size. Using the previously determined values of $D$ and $k^{\ominus}$ and the known value of $[A]$, the cyclic voltammetry response of an electrode of surface area $1 \mathrm{~cm}^{2}$ can be simulated (using the finite diffusion facility) for a range of $R_{p}$ values at each scan rate. For each value of $R_{p}$, a corresponding value of $I_{p}{ }^{c}$ can be determined. Because the simulation is for an electrode area of $1 \mathrm{~cm}^{2}$, dividing the experimental $I_{p}{ }^{c}$ by the simulated $I_{p}^{c}$ gives a ratio that is equal in magnitude to the equivalent area in $\mathrm{cm}^{2}$. For example, in the case of $R_{p}=10 \mu \mathrm{m}$ and $v=0.1 \mathrm{~V} \mathrm{~s}^{-1}$ the simulated peak cathodic current is $0.092 \mathrm{~mA}$. The corresponding experimental voltammogram is Figure $6(\mathrm{~b})$. Dividing the experimental peak current $(2.14 \mathrm{~mA})$ by $0.092 \mathrm{~mA}$ gives the number 23.3. Therefore, if the porous electrode had an average pore radius size of $10 \mu \mathrm{m}$, it would require a total surface area of $23.3 \mathrm{~cm}^{2}$ to generate a peak current of $2.14 \mathrm{~mA}$ at $0.1 \mathrm{~V} \mathrm{~s}^{-1}$ in the given redox system. Using this approach, a plot of equivalent area vs. pore size can be produced for each scan rate, as shown by the curves in Figure 7, each curve corresponding to a different scan rate. At high values of $R_{p}$, diffusion layer overlap does not occur. In this case mass transport is described by semi-infinite diffusion and the peak current is independent of pore size, so a horizontal line is observed in the equivalent area vs. pore size plot. As the pore size decreases, a transition to finite diffusion occurs, resulting in increasing amounts of diffusion layer overlap. The equivalent area increases as the peak currents are smaller than those obtained under semi-infinite diffusion. Because scan rate directly 
affects diffusion layer thickness, the equivalent area vs. pore size plots change with scan rate. As such, the surface area and average pore size of the experimental electrode are determined by where the curves intersect in Figure 7. This is the only point unique to all scan rates for the individual felt employed as the electrode, in this case $10 \mathrm{~cm}^{2}$ and $30 \mu \mathrm{m}$ respectively. Thus, using a simple approximation for pores and a rapid simulation method in commercially available software, estimates for the electrode surface area and average pore size can be determined from cyclic voltammetry experiments with a known redox couple.

\section{Results and Discussion}

The cyclic voltammetry of four redox systems were studied: ferricyanide in $0.1 \mathrm{M} \mathrm{KNO}_{3}$; ferrocyanide in $1 \mathrm{M} \mathrm{KCl}(\mathrm{aq})$, vanadium(V) oxide in $4 \mathrm{M} \mathrm{H}_{2} \mathrm{SO}_{4}(\mathrm{aq})$ and ferrocene in $0.1 \mathrm{M}$ TBAP / acetonitrile. By comparing the voltammograms from experiments using $3 \mathrm{~mm}$ carbon electrodes (EPPG, BPPG and PFCE) with simulations produced using the DigiElch software; it was possible to determine both $D$ and $k^{\ominus}$ for each redox system studied. Values for both $D$ and $k^{\ominus}$ were obtained for a range of scan rates between $10 \mathrm{mV} \mathrm{s}^{-1}$ and $1 \mathrm{~V} \mathrm{~s}^{-1}$. Average values are given in Table 1 and compare well with values previously reported (the values of $k^{\ominus}$ for the GF electrodes in Table 1 are discussed later) [25-27].

\subsection{Ferricyanide Voltammetry}

Figure 8(a) illustrates cyclic voltammograms at $0.05 \mathrm{~V} \mathrm{~s}^{-1}$ for the PFC and EPPG electrodes in an aqueous solution of $1.0 \mathrm{mM}$ ferricyanide and $0.1 \mathrm{M} \mathrm{KNO}_{3}$. Figure $8(\mathrm{~b})$ illustrates the corresponding voltammogram for a graphite felt electrode under the same conditions but where the ferricyanide concentration is $0.1 \mathrm{mM}$. The lower concentration was used to avoid the requirement for $I R$ compensation (see the Supporting Information for more details). There are two main differences between the felt and disc voltammetry. First, the currents recorded with the felt electrode are much higher in magnitude than for the traditional carbon disc electrodes. This is to be expected as the surface area is much larger for the felt electrode. Second, the peaks in the felt voltammogram are better defined, with the current almost returning to the baseline after the peak, resembling thin layer voltammetry [19].

Figure 8(c) illustrates cyclic voltammograms recorded at $0.05 \mathrm{~V} \mathrm{~s}^{-1}$ in an aqueous solution of $0.1 \mathrm{mM}$ ferricyanide and $0.1 \mathrm{M} \mathrm{KNO}_{3}$ with 3 different GF electrodes. As observed, the GF electrodes demonstrate good repeatability in terms of the shape and magnitude of the signal. This is a result of the GF preparation method, specifically the 3 step pre-wetting of the electrode. Without the pretreatment, the GF electrodes produce signals with a reduced magnitude (compared to Figure $8(c)$ ) and poor repeatability. Figure 8(d) illustrates a cyclic voltammogram recorded at $0.05 \mathrm{~V} \mathrm{~s}^{-1}$ in an aqueous solution of $0.1 \mathrm{mM}$ ferricyanide and $0.1 \mathrm{M} \mathrm{KNO}_{3}$ with just the platinum wire fish hook as the working electrode (i.e. no GF). Also shown is the corresponding voltammogram for a GF electrode immersed in supporting electrolyte only. These two voltammograms show the signal observed in Figures $8(b)$ and (c) are predominantly due to ferricyanide redox reactions occurring on GF. On increasing the scan rate, the expected transition in voltammetry characteristics from thinlayer to semi-infinite diffusion was observed. This is discussed in more detail in the Supporting Information. 
The simulation method described in the previous section was combined with the experimental peak currents (at multiple scan rates) and used to generate plots of equivalent surface area vs. average pore size, as shown in Figure 9. Initially, the simulations used the $D$ and $k^{\ominus}$ values for the PFC electrode/ferricyanide system in Table 1 . This generated a similar plot to Figure 7 , and suggested the $0.5 \mathrm{~V} \mathrm{~s}^{-1}$ and $1 \mathrm{~V} \mathrm{~s}^{-1}$ experimental scans corresponded to semi-infinite diffusion mass transport (i.e. the $0.5 \mathrm{~V} \mathrm{~s}^{-1}$ and $1 \mathrm{~V} \mathrm{~s}^{-1}$ curves were horizontal at the curve crossing point). Therefore, an average $k^{\theta}$ value of $2.2 \times 10^{-3} \mathrm{~cm} \mathrm{~s}^{-1}$ was obtained by fitting the peak to peak separation values for the $0.5 \mathrm{~V} \mathrm{~s}^{-1}$ and $1 \mathrm{~V} \mathrm{~s}^{-1} \mathrm{GF}$ experimental voltammograms to simulated semi-infinite diffusion cyclic voltammograms using DigiElch. This is another benefit of the simulation method - the identification of experimental data where mass transport is described by semi-infinite diffusion. Figure 9 was then generated using values of $D=7.5 \times 10^{-6} \mathrm{~cm}^{2} \mathrm{~s}^{-1}$ and $k^{\ominus}=2.2 \times 10^{-3} \mathrm{~cm} \mathrm{~s}^{-1}$. As observed, the curves (representing different scan rates) intersect at around $50 \mathrm{~cm}^{2}$ and $30 \mu \mathrm{m}$ in Figure 9, implying these are the values of electrochemical surface area and average pore radius for the particular GF tested.

A more precise range for the cross-over region is given in Table 2, along with the surface area calculated from the cylinder approximation and the corresponding approximate pore radius. Also given are the results for 2 other GF electrodes in the same electrolyte. It is clear from table that there is good agreement between experimentally determined and theoretically predicted surface areas, suggesting the approximations used in the model are a good first attempt at describing the complex electrode surface arrangement inside the porous electrode. Regarding the experimental pore sizes, these are similar to the theoretical pore sizes but the theoretical pore sizes tend to be consistently smaller than the experimental values. This is to be expected as the experimental result is a summation of an ensemble of pores where the larger pores have a disproportionally larger contribution to the peak current (as they have less thin layer and more semi-infinite diffusion-type voltammetry). Assuming the pore size distribution follows a Gaussian curve, the experimental result represents a pore size that is larger than the median whereas the theoretical result represents the median (or a size closer to the median if the distribution isn't symmetrical). Further work will address this issue, where the GF electrode will be modelled as an ensemble of tubular pores.

\subsection{Other Redox Systems}

In addition to ferricyanide, 3 other redox systems were investigated: ferrocyanide in $1 \mathrm{M} \mathrm{KCl}(\mathrm{aq})$; vanadium(V) oxide in $4 \mathrm{M} \mathrm{H}_{2} \mathrm{SO}_{4}(\mathrm{aq})$; and ferrocene in $0.1 \mathrm{M} \mathrm{TBAP}$ / acetonitrile. Following the same procedure in the previous section, cyclic voltammograms were recorded with GF working electrodes at different scan rates. The results were then analysed using the simulation method discussed previously. This generated experimental values for the equivalent pore radius and surface area, which are reported in Table 2. The voltammetry and analysis followed the same trends as shown above for the ferricyanide system and more details are provided in the Supporting Information. For all the systems there was good agreement between the experimental and theoretical surface area, generating more confidence in the simulation method (especially given the diverse selection of redox systems). As before, the experimental average pore radius values were similar to but consistently larger than their theoretical analogues.

Of particular interest was the vanadium(V) oxide redox system, described by equation 9:

$$
\mathrm{VO}_{2}^{+}{ }_{(\mathrm{aq})}+\mathrm{e}^{-}+2 \mathrm{H}^{+}{ }_{(\mathrm{aq})} \rightleftharpoons \mathrm{VO}^{2+}{ }_{(\mathrm{aq})}+\mathrm{H}_{2} \mathrm{O}
$$


This system is well known to produce poor quality voltammograms with traditional carbon disc working electrodes and offers an excellent opportunity to showcase the ability of the GF electrodes. Figure 10(a) shows the cyclic voltammogram for $1.6 \mathrm{mM}$ vanadium( $\mathrm{V}$ ) oxide in $4 \mathrm{M} \mathrm{H}_{2} \mathrm{SO}_{4}(\mathrm{aq})$ with a PFC working electrode at $50 \mathrm{mV} \mathrm{s}^{-1}$. In comparison Figure 10(b) shows the cyclic voltammogram for the same solution but with a GF electrode. The GF is clearly superior at both resolving the redox peaks and improving the profile of the voltammogram. The GF felt was also able to distinguish the redox peaks of a $32 \mu \mathrm{M}$ solution of the vanadium(V), shown in Figure $10(\mathrm{c})$. It was not possible to distinguish these redox peaks with the 3 carbon disc electrodes at this low concentration. Given the challenging nature of this redox system, the ability of the GF electrode to distinguish peaks at such minute concentrations is particularly impressive.

\subsection{Fibre Surface Structure}

The capacitance of an electrode surface can be determined via cyclic voltammetry within a potential window where no faradaic reactions occur. The experimental method is relatively straight forward and more details are given in the Supporting Information (along with experimental examples).

Once the capacitance, $C$, of the GF electrode is determined, the specific capacitance, $C^{\circ}$, can be evaluated by dividing the capacitance value by the total area of the electrode, these are listed in Table 3 where the theoretical surface area was used. The results provide an insight into the nature of the carbon fibre surfaces of the graphite felt. Previous studies with highly ordered pyrolytic graphite [28], found graphite with a predominantly basal plane surface has a specific capacitance of around 1-2 $\mu \mathrm{F} \mathrm{cm}^{-2}$, whereas for edge plane surfaces the figure is a lot higher, around $70 \mu \mathrm{F} \mathrm{cm}^{-2}$. In addition when a carbon surface is comprised of both edge and basal plane, the total specific capacitance, $C^{\circ}$, is a weighted average of the edge and basal plane contributions:

$$
C^{\circ}=C^{\circ} f_{\mathrm{e}}+C^{\circ}{ }_{\mathrm{b}}\left(1-f_{\mathrm{e}}\right)
$$

where $C^{\circ}$ and $C^{\circ}$ are the specific capacitance values for the edge and basal plane surfaces, and $f_{\mathrm{e}}$ is the fraction of edge plane on the graphite surface.

The results from Table 3 indicate the average specific capacitance of the GF electrode is relatively low, around $10 \mu \mathrm{F} \mathrm{cm}^{-2}$ over the four systems studied in this work. Using equation 10 and values of $70 \mu \mathrm{F} \mathrm{cm}^{-2}$ and $1 \mu \mathrm{F} \mathrm{cm}^{-2}$ for $C^{\circ}{ }_{e}$ and $C^{\circ}{ }_{b}$, respectively, this corresponds to an approximate basal/edge ratio of $87 / 13$ (i.e. $87 \%$ basal plane, $13 \%$ edge plane) and suggests that basal plane carbon is the dominant surface structure in the GFs studied in this work. This agrees well with the 'onion ring' structure observed in highly graphitized carbon fibres derived from polyacrylonitrile [29].

\subsection{Limit of Detection}

An unexpected application of this method is the ability to detect extremely low concentrations of redox active species. Figure 11 illustrates cyclic voltammograms recorded at $0.05 \mathrm{~V} \mathrm{~s}^{-1}$ in ferrocene in 0.1 M TBAP / acetonitrile solutions for the EPPG electrode and a graphite felt electrode. In the case of the EPPG electrode, the ferrocene concentration is $10 \mu \mathrm{M}$. At this concentration, the baseline/background signal is noticeable and encroaches on the redox signal. For this electrode, the redox signal became difficult to identify between 1 and $10 \mu \mathrm{M}$, in agreement with the expected limit of detection value [27]. In the case of the graphite felt voltammogram, the ferrocene concentration is $0.5 \mu \mathrm{M}, 20$ times lower than that in figure 11(a) (EPPG electrode). Although the background 
current is relatively high, the baseline is virtually horizontal and the redox signal is very prominent. Indeed, the redox signal could still be identified at $0.1 \mu \mathrm{M}$ ferrocene (not shown). The initial studies with GF electrodes have shown very promising limits of detection; typically 10-100 times lower than the EPPG electrode. Note that traditional disc electrodes modified with porous layers have also been shown to give well defined voltammetry peaks leading to better detection limits [30-33]. This has recently been simulated and explained in detail by Compton and co-workers [34]. However, the currents at these electrodes are considerably smaller than those recorded in the present study, due to the much higher surface area of a $1 \mathrm{~cm} \times 1 \mathrm{~cm}$ section of graphite felt.

The clear signal obtained with the GF electrode at such a low concentration of redox species suggests this electrode may have promising applications in electroanalysis, with the capability to achieve lower limits of detection than present electrodes. The ability to detect low concentrations of redox species with an electrode of large surface area where mass transport is described by planar diffusion contradicts current trends in electroanalysis, where limits of detection are lowered via the use of small electrodes, and the signal to noise ratio is increased as a result of the high mass transport rates associated with micro/nano electrodes [35-36]. There are several factors believed to allow such low concentrations to be measured with the GF electrode. First, the capacitance measurements suggest the electrode surface is largely composed of basal plane sites, suggesting similarity to a basal plane HOPG electrode. HOPG electrodes are well known to have flat or even "perfect" baselines in voltammetric signals [27]. This property helps increase the signal-to-noise ratio. Second, the heavily overlapping diffusion layers within pores lead to thin layer voltammetry characteristics, producing more clearly defined peaks. Finally, the high surface area of the felts leads to relatively large currents for a given redox species concentration. For example, a $3 \mathrm{~mm}$ diameter disc electrode used at $0.05 \mathrm{~V} \mathrm{~s}^{-1}$ would typically produce a faradaic current of $\sim 10 \mu \mathrm{A}$ for a $1 \mathrm{mM}$ solution of redox species and consequently $\sim 10 \mathrm{nA}$ for a $1 \mu \mathrm{M}$ solution. In contrast, the GF electrode area is nearly 1000 times greater $\left(0.07 \mathrm{~cm}^{2}\right.$ vs $\left.60 \mathrm{~cm}^{2}\right)$. Consequently, the reduction/oxidation faradaic currents are almost 1000 times greater with $\sim 10 \mathrm{~mA}$ and $\sim 10 \mu \mathrm{A}$ for $1 \mathrm{mM}$ and $1 \mu \mathrm{M}$ solutions respectively. These larger currents are much easier for the potentiostat to detect and less affected by electrically noisy environments. Thus, the GF electrode represents a new approach to the challenge of limit of detection with considerable cost advantage over "small" electrodes. A follow-up publication will further explore the promising electroanalytical properties of felt electrodes, with particular focus on limit of detection.

\section{Conclusions}

The experimental method outlined in this study allows GF electrodes to be used in quiescent electrochemical experiments yielding well-defined voltammetric peak signals. When the resulting experimental voltammograms are combined with simulations, several key properties of the GF can be determined. These include the electrochemical surface area, the average pore size and the $k^{\ominus}$ values for a range of redox systems. Capacitance measurements reveal the chemical nature of the carbon surface.

To fully exploit the electroanalytical applications of the GF electrodes, a more robust simulation method is required. This will involve generating a 1D model based on radial coordinates rather than the Cartesian coordinates used in the current software and modelling the GF electrode as an ensemble of tube electrodes of different radii. This will more closely match the physical properties of 
the GF, improving the accuracy of the simulation method and increasing confidence in the model. Even with the basic assumptions used in this paper, the electroanalytical results presented justify the use of porous carbon electrodes in quiescent electrochemistry and open up a number of further areas of work.

\section{Acknowledgements}

Robert Smith would like to thank the ERDF, the Centre for Global Eco-innovation and ACAL Energy for the research studentship. The authors would also like to thank Dr Casper Kunstmann for his assistance with SEM imaging and Rüdiger Schweiss and Dirk Schneider of SGL Group for their advice and support. 


\section{References:}

[1] A.Z. Weber, M.M. Mench, J.P. Meyers, P.N. Ross, J.T. Gostick, Q. Liu, Redox flow batteries: a review, J. Appl. Electrochem. 41 (2011) 1165-1166.

[2] P. Zhao, H. Zhang, H. Zhou, B. Yi, Nickel foam and carbon felt applications for sodium polysulfide/bromine redox flow battery electrodes, Electrochimica Acta. 51 (2005) 1091-1098.

[3] T. Wu, K. Huang, S. Liu, S. Zhuang, D. Fang, S. Li, D. Lu, A. Su, Hydrothermal ammoniated treatment of PAN-graphite felt for vanadium redox flow battery, J. Solid State Electrochem. 16 (2012) 579-585.

[4] A.A. Shah, M.J. Watt-Smith, F.C. Walsh, A dynamic performance model for redox-flow batteries involving soluble species, Electrochimica Acta. 53 (2008) 8087-8100.

[5] A. Di Blasi, O. Di Blasi, N. Briguglio, A.S. Aricò, D. Sebastián, M.J. Lázaro, G. Monforte, V. Antonucci, Investigation of several graphite-based electrodes for vanadium redox flow cell, J. Power Sources. 227 (2013) 15-23.

[6] M. H. Chakrabarti, N. P. Brandon, S.A. Hajimolana, F. Tariq, V. Yufit, M.A. Hashim, M.A. Hussain, C. T. J. Low, P. V. Aravind, Application of carbon materials in redox flow batteries, J. Power Sources. 253 (2014) 150-166.

[7] N. Vatistas, P.F. Marconi, M. Bartolozzi, Mass-transfer study of the carbon felt electrode, Electrochimica Acta. 36 (1991) 339-343.

[8] D. You, H. Zhang, J. Chen, A simple model for the vanadium redox battery, Electrochimica Acta. 54 (2009) 6827-6836.

[9] Q. Xu, T.S. Zhao, Determination of the mass-transport properties of vanadium ions through the porous electrodes of vanadium redox flow batteries, Phys. Chem. Chem. Phys. 15 (2013) 1084110848.

[10] W.H. Wang, X.D. Wang, Investigation of Ir-modified carbon felt as the positive electrode of an all-vanadium redox flow battery, Electrochimica Acta. 52 (2007) 6755-6762.

[11] X. Li, K. Huang, S. Liu, N. Tan, L. Chen, Characteristics of graphite felt electrode electrochemically oxidized for vanadium redox battery application, Trans. Nonferrous Met. Soc. China. 17 (2007) 195199.

[12] W. Zhang, J. Xi, Z. Li, H. Zhou, L. Liu, Z. Wu, X. Qiu, Electrochemical activation of graphite felt electrode for VO2+/VO2+ redox couple application, Electrochimica Acta. 89 (2013) 429-435.

[13] D. A. C. Brownson, L. C. S. Figueiredo-Filho, X. Ji, M. Gomez-Mingot, J. Iniesta, O. Fatibello-Filho, D.K. Kampourisa, C. E. Banks, Freestanding three-dimensional graphene foam gives rise to beneficial electrochemical signatures within non-aqueous media, J. Mater. Chem. A. 1 (2013) 5962-5972,

[14] K. Kinoshita, S. Leach, Mass-Transfer Study of Carbon Felt, Flow-Through Electrode, J. Electrochem. Soc. 129 (1982). 1993-1997 
[15] B. Delanghe, S. Tellier, M. Astruc, Mass transfer to a carbon or graphite felt electrode, Electrochimica Acta. 35 (1990) 1369-1376.

[16] N. Parikh, J. S. Allen, R. S. Yassar, Microstructure of Gas Diffusion Layers for PEM Fuel Cells, Fuel Cells, 12 (2012) 382-390

[17] C. Amatore, J. Saveant, J.M. Savéant, D. Tessier, Charge transfer at partially blocked surfaces, J. Electroanal. Chem. 147 (1983) 39-51.

[18] M. Rudolph, D.P. Reddy, S.W. Feldberg, A Simulator for Cyclic Voltammetric Responses, Anal. Chem. 66 (1994) 589A-600A.

[19] A.J. Bard, L.R. Faulkner, Electrochemical Methods: Fundamentals and Applications, second ed., Wiley Global Education, 2000.

[20] T.J. Davies, R.G. Compton, The cyclic and linear sweep voltammetry of regular and random arrays of microdisc electrodes: Theory, J. Electroanal. Chem. 585 (2005) 63-82.

[21] T.J. Davies, S. Ward-Jones, C.E. Banks, J. del Campo, R. Mas, F. X. Muñoz, R. G. Compton, The cyclic and linear sweep voltammetry of regular arrays of microdisc electrodes: Fitting of experimental data, J. Electroanal. Chem. 585 (2005) 51-62.

[22] B. Brookes, T. Davies, A. C. Fisher, R. G. Evans, S. J. Wilkins, K. Yunus, J. D. Wadhawan, R. G. Compton, A Computational and experimental study of the cyclic voltammetry response of partially blocked electrodes. Part 1. Nonoverlapping, uniformly distributed blocking, J. Phys. Chem. B. 107 (2003) 6431-6444.

[23] T.J. Davies, B.A. Brookes, A.C. Fisher, K. Yunus, S.J. Wilkins, P.R. Greene, J.D. Wadhawan, R.G. Compton, A Computational and Experimental Study of the Cyclic Voltammetry Response of Partially Blocked Electrodes. Part II: Randomly Distributed and Overlapping Blocking Systems, J. Phys. Chem. 107 (2003) 1616-1627.

[24] T.J. Davies, R.R. Moore, C.E. Banks, R.G. Compton, The cyclic voltammetric response of electrochemically heterogeneous surfaces, J. Electroanal. Chem. 574 (2004) 123-152.

[25] L. Hui-jun, X. Qian, Y. Chuan-wei, C. Ya-zhe, Q. Yong-lian, The effect of temperature on the electrochemical behaviour of the V (IV)/V (V) couple on a graphite electrode, Int. J. Electrochem. Sci. 6 (2011) 3483-3496.

[26] Y. Wang, E.I. Rogers, R.G. Compton, The measurement of the diffusion coefficients of ferrocene and ferrocenium and their temperature dependence in acetonitrile using double potential step microdisk electrode chronoamperometry, J. Electroanal. Chem. 648 (2010) 15-19.

[27] R.L. McCreery, Carbon Electrodes: Structural Effects on Electron Transfer Kinetics, in: A. J Bard (Ed.), Electroanalytical Chemistry, volume 17, Marcel Dekker, New York, 1990, pp. 221-364

[28] R.J. Rice, R.L. McCreery, Quantitative relationship between electron transfer rate and surface microstructure of laser-modified graphite electrodes, Anal. Chem. 61 (1989) 1637-1641. 
[29] F. Beguin, E. Frackowiak, Carbons for Electrochemical Energy Storage and Conversion Systems, CRC Press, 2009.

[30] R. Szamocki, S. Reculusa, S. Ravaine, P.N. Bartlett, Alex, A. Kuhn, R. Hemplemann, Tailored Mesostructuring and Biofunctionalization of Gold for Increased Electroactivity, Angew. Chem. Int. Ed. 45 (2006) 1317-1321.

[31] X. Chen, Y. Wang, J. Zhou, W. Yan, X. Li, J. J. Zhu, Electrochemical impedance immunosensor based on three-dimensionally ordered macroporous gold film, Anal. Chem. 80 (2008) 2133-2140.

[32] X. Chen, J. Zhou, J. Xuan, W. Yan, L. P. Jiang, J. J. Zhu, Room-temperature ionic liquid assisted fabrication of sensitive electrochemical immunosensor based on ordered macroporous gold film, Analyst. 135 (2010) 2629.

[33] X. Chen, J. Xuan, L. P. Jiang, J. J. Zhu, Preparation of the glucose sensor based on threedimensional ordered macroporous gold film and room temperature ionic liquid, Sci. China Ser. BChem. 52 (2009) 1999-2005.

[34] E.O. Barnes, X. Chen, P. Li, R.G. Compton, Voltammetry at porous electrodes: A theoretical study, J. Electroanal. Chem 720-721 (2014) 92-100.

[35] N.J. Freeman, R. Sultana, N. Reza, H. Woodvine, J.G. Terry, A.J. Walton, C.L. Brady, I. Schmueser, A.R. Mount, Comparison of the performance of an array of nanoband electrodes with a macro electrode with similar overall area, Phys.I Chem. Chem.I Phys. 15 (2013) 8112.

[36] R. Sultana, N. Reza, N.J. Kay, I. Schmueser, A.J. Walton, J.G. Terry, A.R. Mount, N.J.Freeman, Practical Implications of using Nanoelectrodes for Bioanalytical Measurements, Electrochimica Acta. 126 (2014) 98-103. 


\section{$\underline{\text { Figure captions }}$}

Figure 1. Image of water droplet on graphite felt (SGL GFD2.5), taken $30 \mathrm{~s}$ after the water drop was deposited on the felt surface.

Figure 2. Image of GF electrode with platinum 'Fishhook' before and after attachment.

Figure 3. SEM images of GF fibres.

Figure 4. Illustration of a theoretical unit cell (a) for evaluating pore radius, $R_{p}$, and fibre to fibre distance, $d$. (b)

Figure 5. Schematic diagram approximating a pore as a tube electrode, which can be approximated as a parallel plate electrode assembly, which is mathematically identical to a planar electrode below an insulating plate.

Figure 6. Simulated cyclic voltammograms for the porous electrode of total surface area $10 \mathrm{~cm}^{2}$ and average pore radius of $30 \mu \mathrm{m}$ in the A-B redox system discussed in the text at scan rates of (a) $0.01 \mathrm{~V} \mathrm{~s}^{-1}$, (b) $0.1 \mathrm{~V} \mathrm{~s}^{-1}$ and (c) $1 \mathrm{~V} \mathrm{~s}^{-1}$.

Figure 7. Simulated curves of equivalent surface area vs. pore radius using the cathodic peak current results from the porous electrode with total surface area $10 \mathrm{~cm}^{2}$ and average pore radius $30 \mu \mathrm{m}$.

Figure 8. Cyclic voltammograms of (a) EPPG and PFC type electrodes in $1.0 \mathrm{mM}$ ferricyanide/0.1 M $\mathrm{KNO}_{3}$ (aq.) solution and (b) GF electrode in $0.1 \mathrm{mM}$ ferricyanide/0.1 $\mathrm{M} \mathrm{KNO}_{3}$ (aq.) solution. Scan rate = $0.05 \mathrm{~V} \mathrm{~s}^{-1}$. (c) Cyclic voltammograms of three different GF electrodes in a $0.1 \mathrm{mM}$ ferricyanide / $0.1 \mathrm{M}$ $\mathrm{KNO}_{3}$ (aq.) solution. Scan rate $=0.05 \mathrm{~V} \mathrm{~s}^{-1}$. (d) Cyclic voltammograms of the platinum wire fish hook in $0.1 \mathrm{mM}$ ferricyanide / $0.1 \mathrm{M} \mathrm{KNO}_{3}$ (aq.) solution and a GF electrode in $0.1 \mathrm{M} \mathrm{KNO}_{3}$ (aq.) solution. Scan rate $=0.05 \mathrm{~V} \mathrm{~s}^{-1}$.

Figure 9. Simulated curves of equivalent surface area vs. pore radius using the cathodic peak current results from a GF electrode in a $0.1 \mathrm{mM}$ ferricyanide solution.

Figure 10. Cyclic voltammetry of (a) PFC electrode, (b) GF electrode in $1.6 \mathrm{mM}$ vanadium(V) / $4 \mathrm{M}$ $\mathrm{H}_{2} \mathrm{SO}_{4}$ (aq.) solution and (c) $\mathrm{GF}$ electrode in $32 \mu \mathrm{M}$ vanadium(V) / $4 \mathrm{M} \mathrm{H}_{2} \mathrm{SO}_{4}$ (aq.) solution. Scan rate $=0.05 \mathrm{~V} \mathrm{~s}^{-1}$.

Figure 11. Cyclic voltammetry of (a) EPPG electrode in $10 \mu \mathrm{M}$ ferrocene solution and (b) GF electrode in $0.5 \mu \mathrm{M}$ ferrocene solution. Scan rate $=0.05 \mathrm{~V} \mathrm{~s}^{-1}$.

\section{$\underline{\text { Table captions }}$}

Table 1. Rate constants $\left(k^{\ominus}\right)$ and diffusion coefficients $(D)$ for EPPG, PFC and GF electrodes.

Table 2. Summary of experimentally determined equivalent surface area and pore radius and theoretical pore radius and surface area.

Table 3. Average specific capacitance measurements for GF in a range of redox systems at various scan speeds $\left(0.1-5 \mathrm{~V} \mathrm{~s}^{-1}\right)$. 
Figure 1

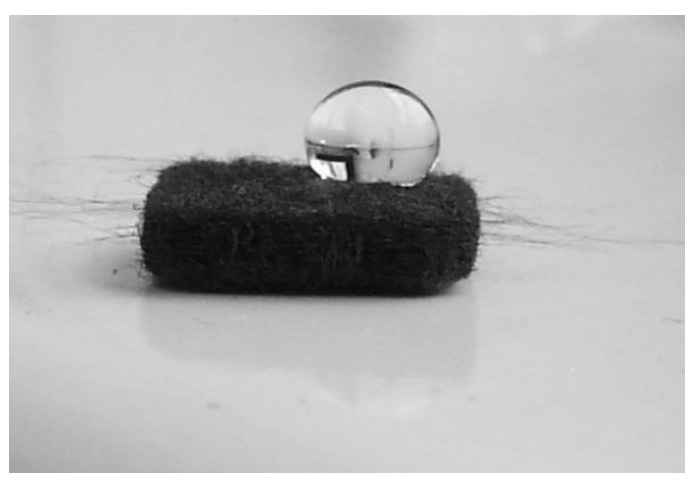

Figure 1 Grayscale

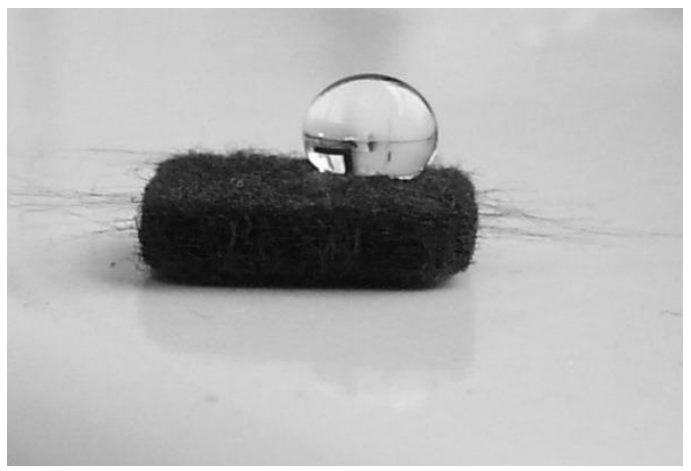


Figure 2

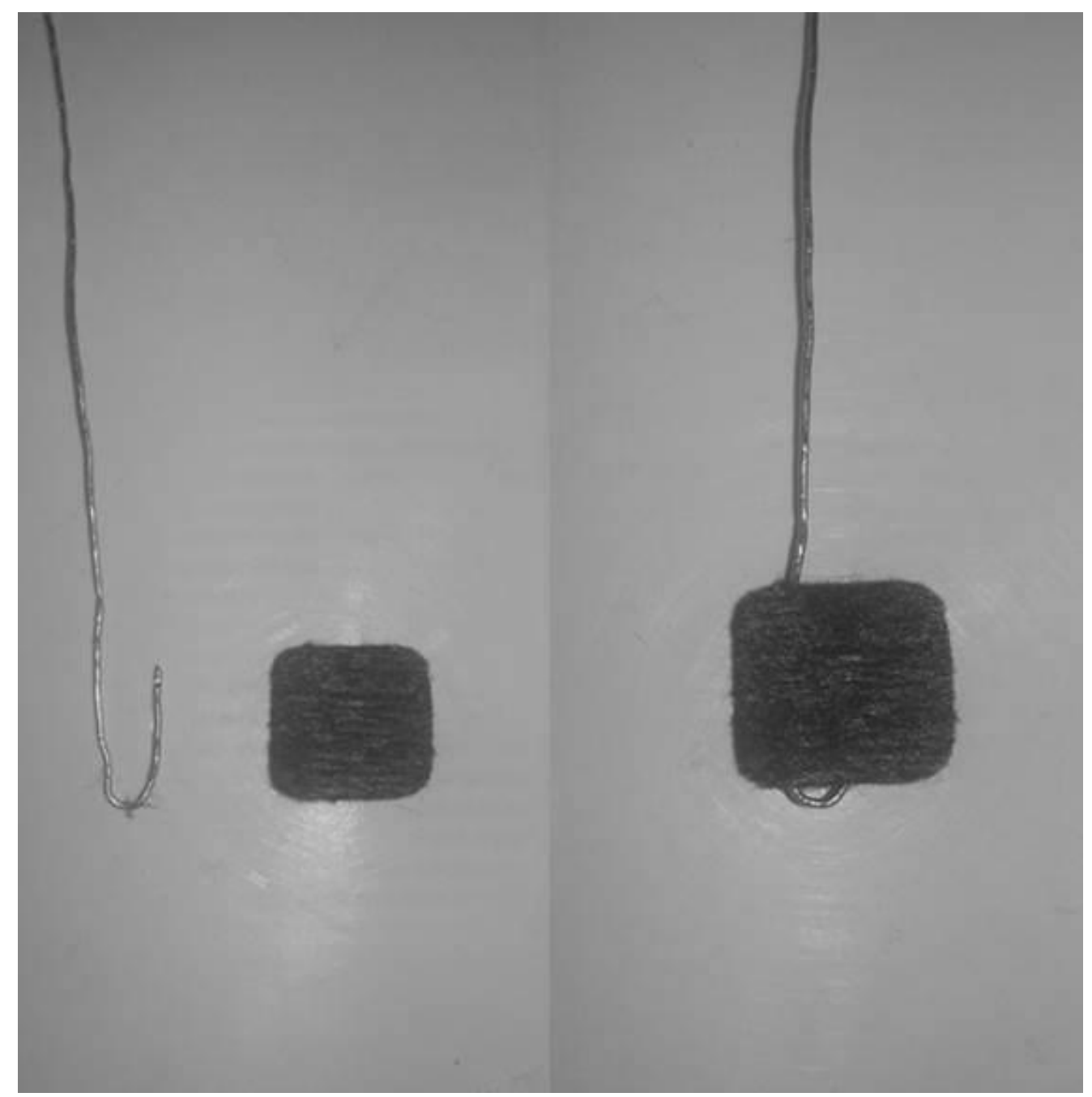


Figure 3

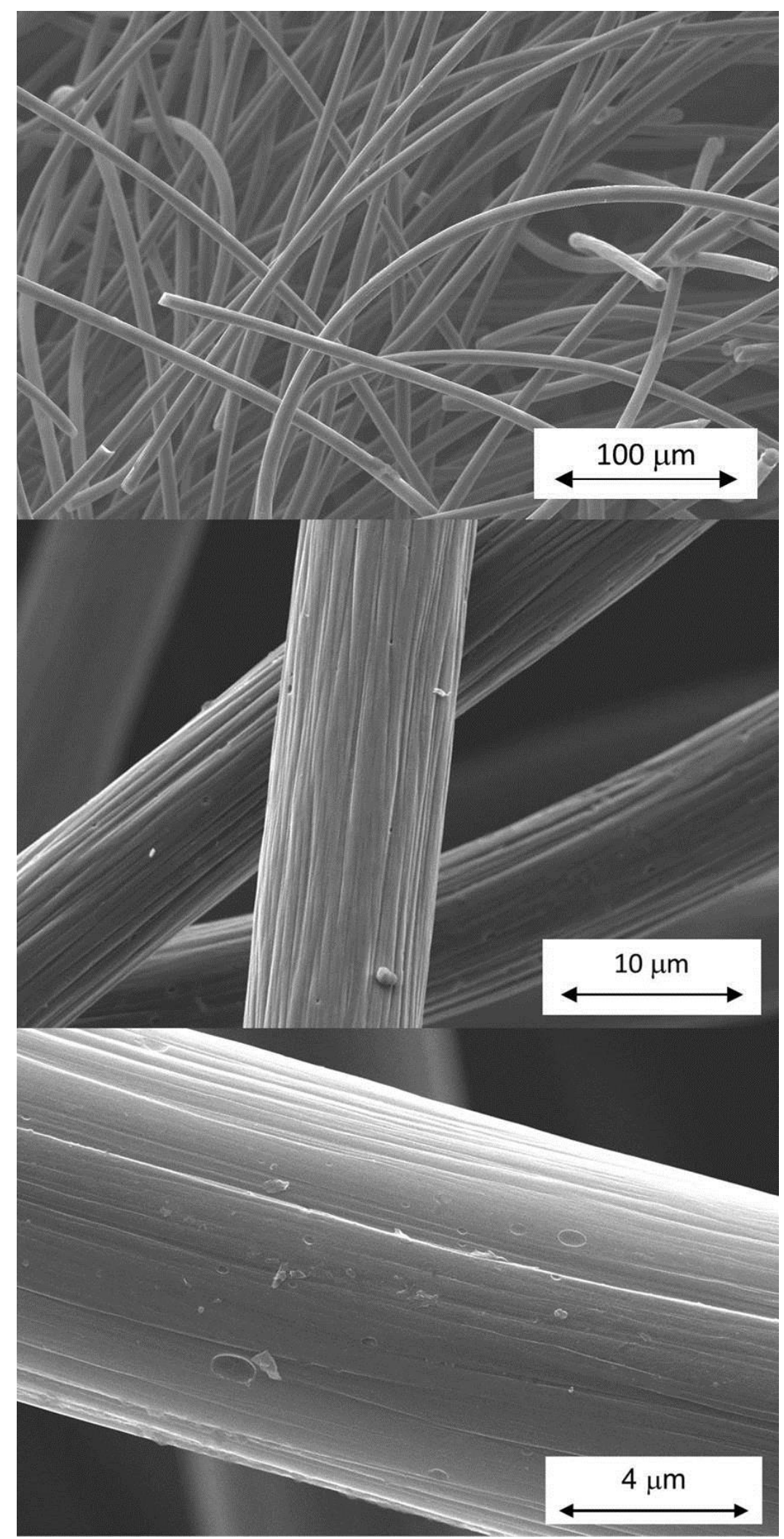


Figure 4

a)

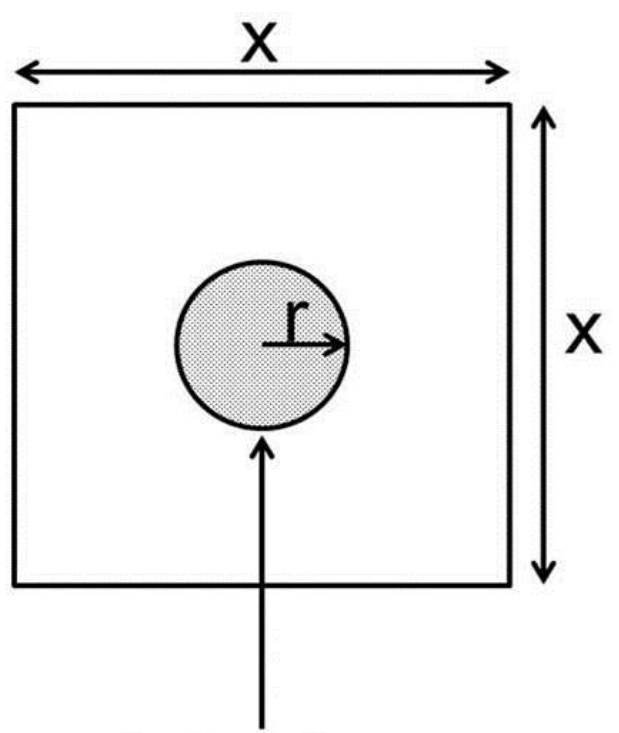

Carbon fibre b)

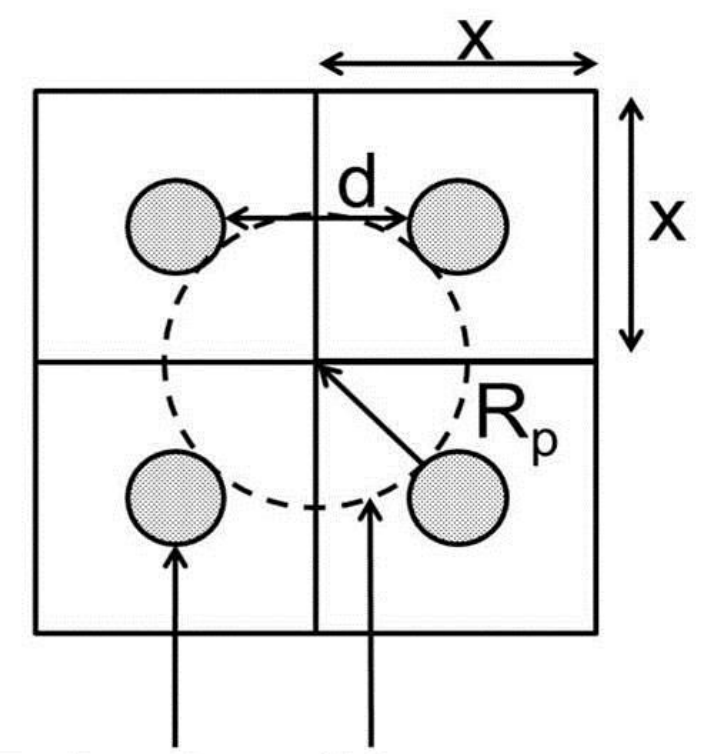

Carbon fibre Pore 
Figure 5

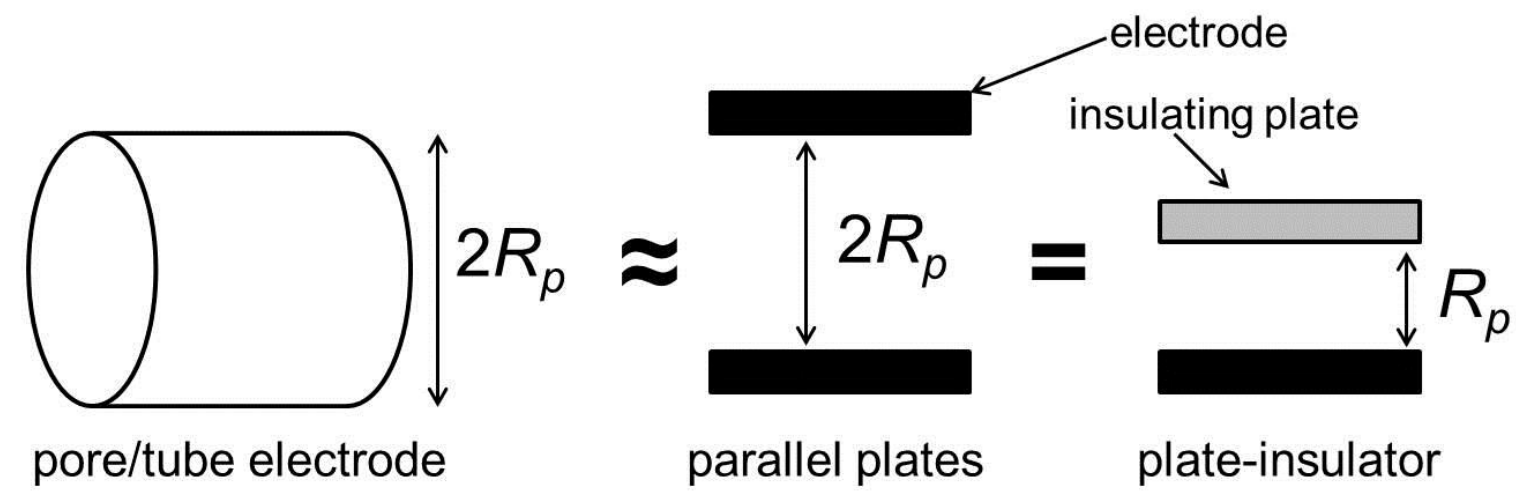


Figure 6
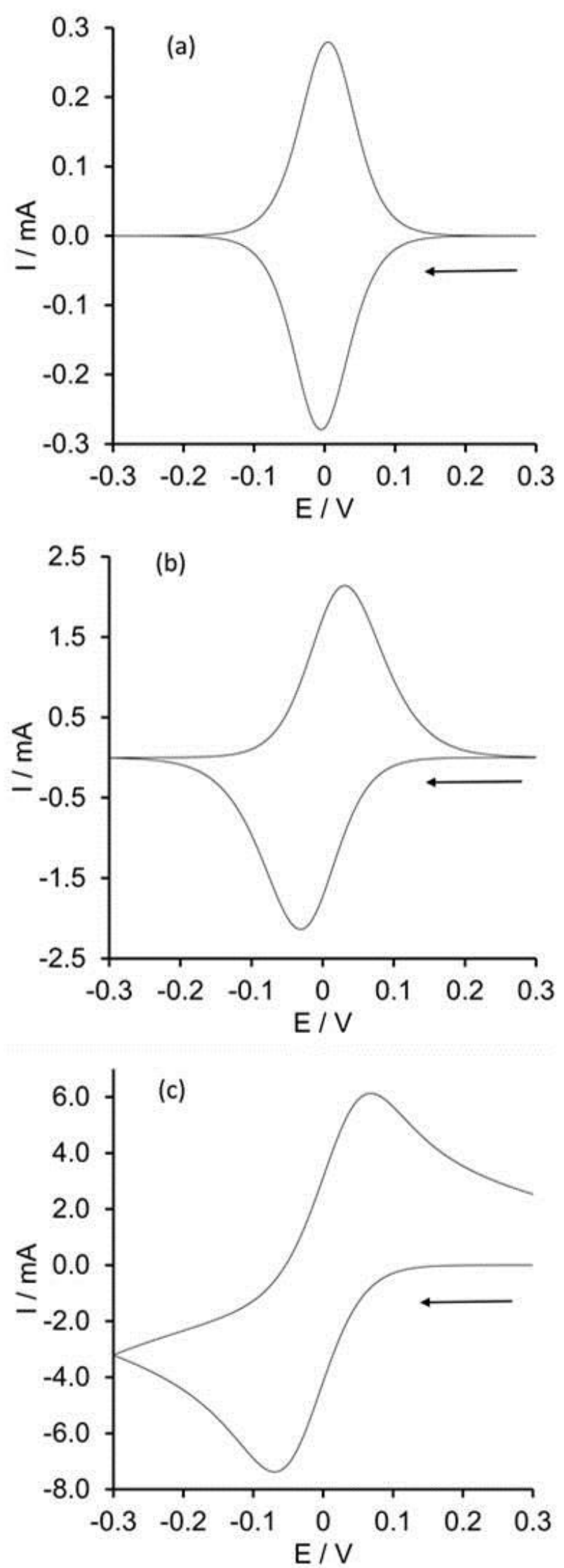
Figure 7

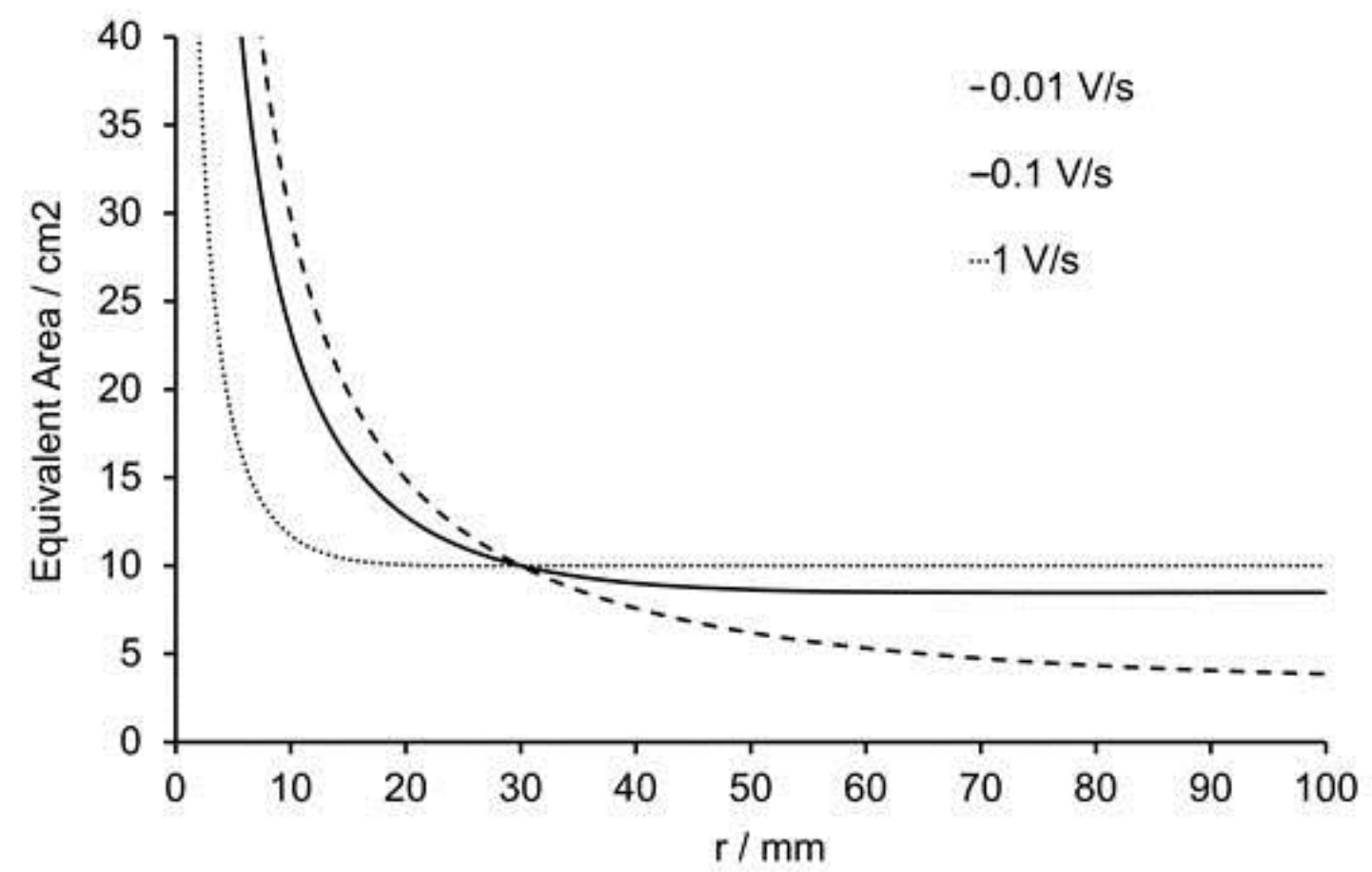


Figure 8
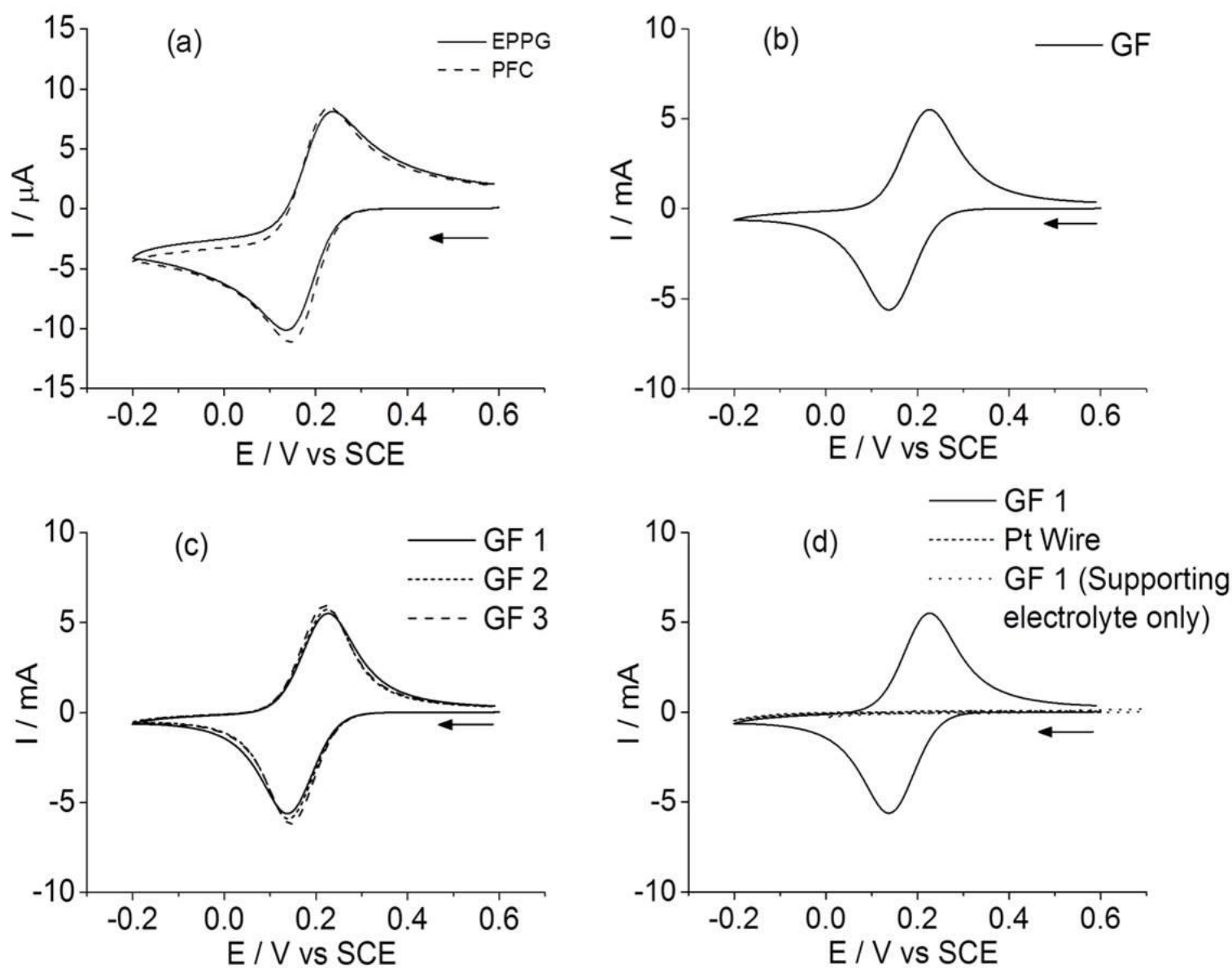
Figure 9

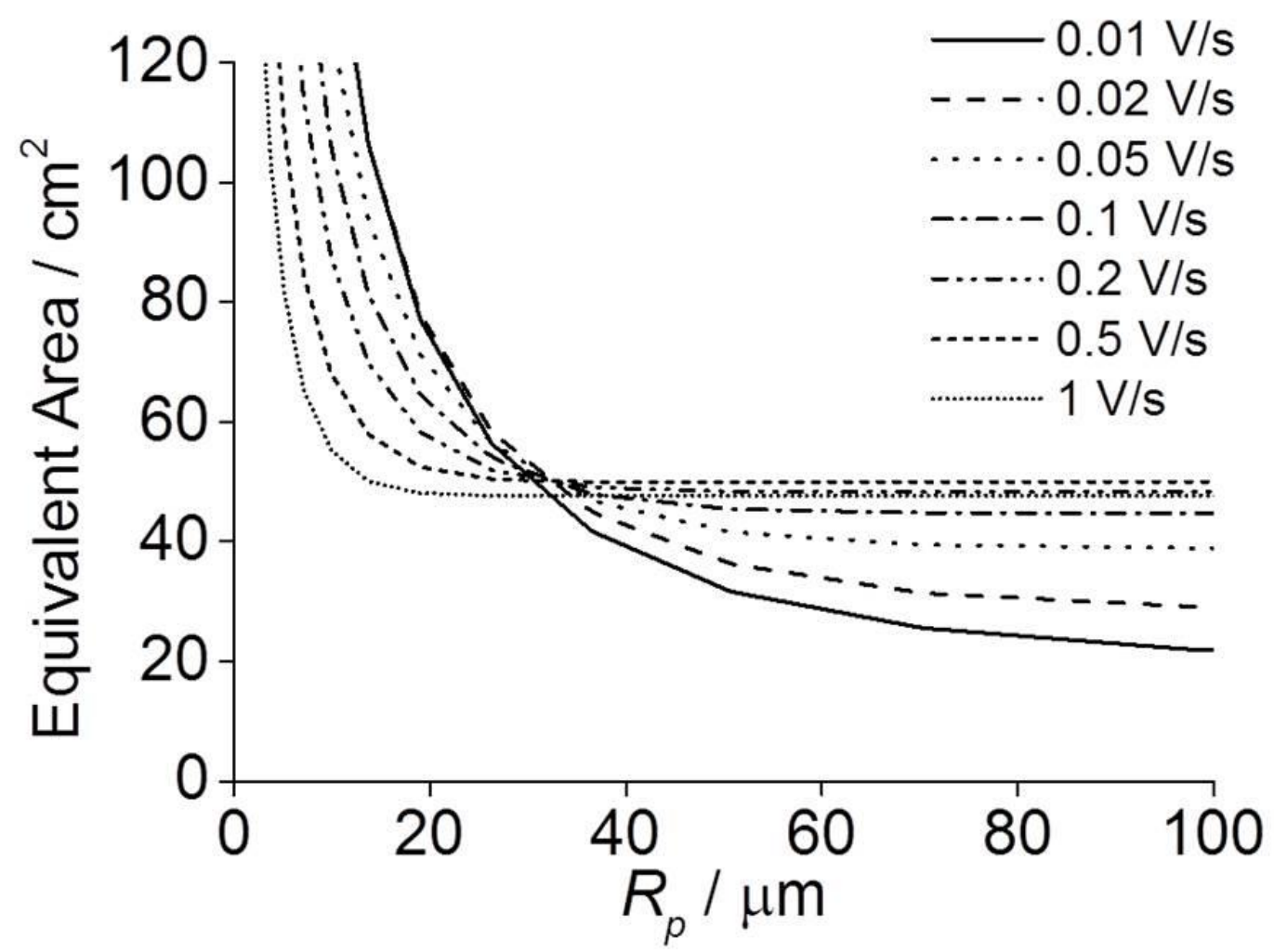


Figure 10
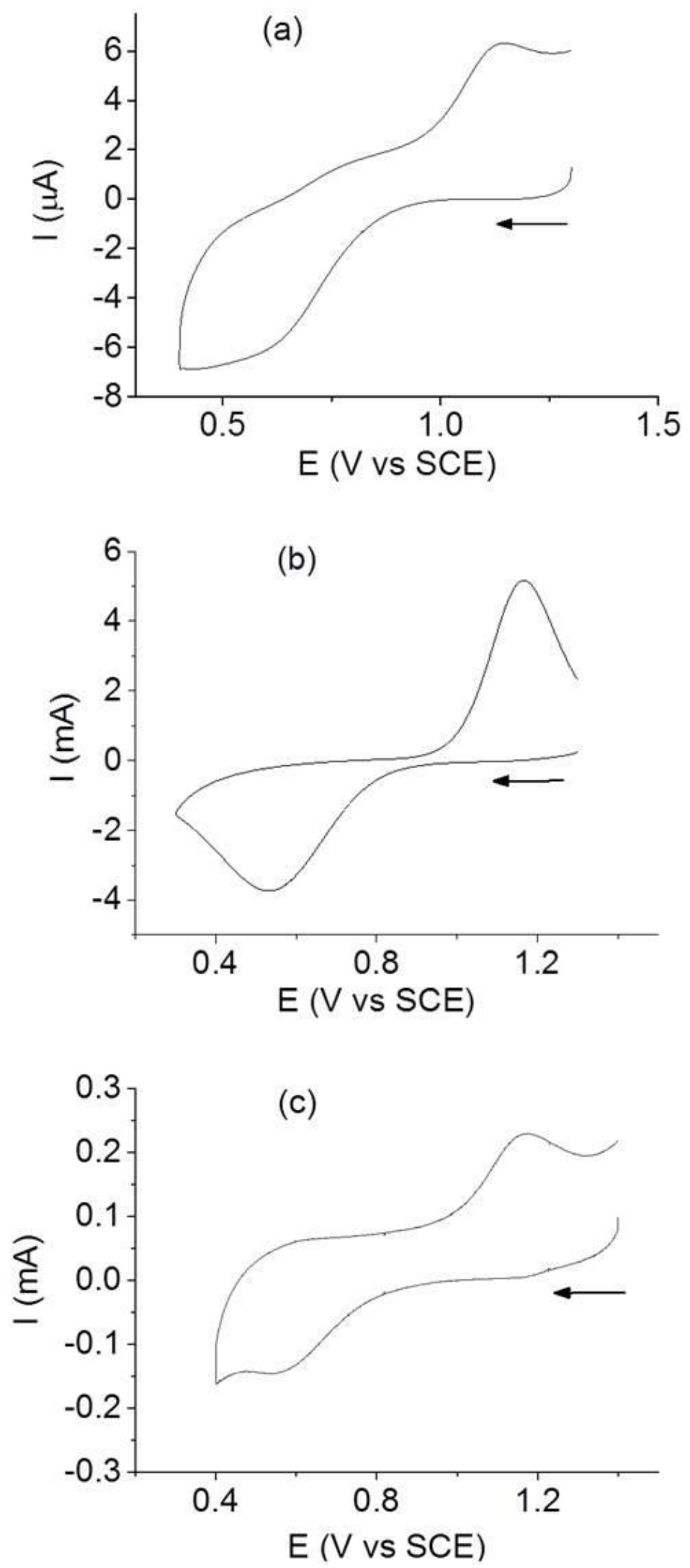
Figure 11
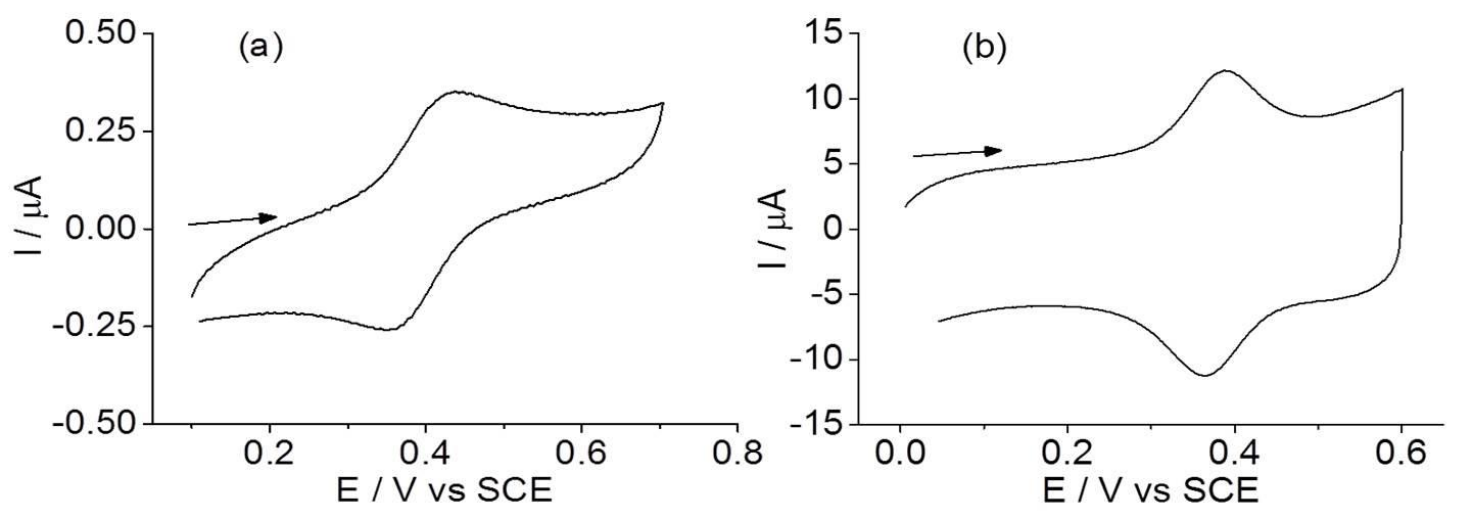
Table 1

\begin{tabular}{|l|c|c|c|c|}
\hline \multirow{2}{*}{ Redox System } & \multicolumn{2}{|c|}{$k^{\circ}$ of different electrodes $\left(\mathrm{cm} \mathrm{s}^{-1}\right)$} & \multirow{2}{*}{$D\left(\mathrm{~cm}^{2} \mathbf{~ s}^{-1}\right)$} \\
\cline { 2 - 5 } & EPPG & PFC & GF & \\
\hline Ferricyanide (aqueous) & $2.3 \pm 0.3 \times 10^{-3}$ & $3.0 \pm 0.5 \times 10^{-3}$ & $2.2 \pm 0.5 \times 10^{-3}$ & $7.5 \pm 0.3 \times 10^{-6}$ \\
\hline Ferrocyanide (aqueous) & $7.5 \pm 0.4 \times 10^{-3}$ & - & $7.0 \pm 0.5 \times 10^{-3}$ & $6.0 \pm 0.2 \times 10^{-6}$ \\
\hline Ferrocene (non-aqueous) & $2.2 \pm 0.3 \times 10^{-2}$ & $3.5 \pm 0.4 \times 10^{-4}$ & $2.0 \pm 0.4 \times 10^{-2}$ & $2.4 \pm 0.2 \times 10^{-5}$ \\
\hline Vanadium(V) (aqueous) & $1.7 \pm 0.3 \times 10^{-5}$ & $2.0 \pm 0.6 \times 10^{-5}$ & $4.1 \pm 0.7 \times 10^{-6}$ & $1.9 \pm 0.5 \times 10^{-6}$ \\
\hline
\end{tabular}


Table 2

\begin{tabular}{|c|c|c|c|c|c|}
\hline $\begin{array}{l}\text { Redox } \\
\text { system }\end{array}$ & $\begin{array}{c}\text { GF } \\
\text { electrode } \\
\text { number }\end{array}$ & $\begin{array}{c}\text { Equivalent } \\
\text { pore radius } \\
(\mu \mathrm{m})\end{array}$ & $\begin{array}{c}\text { Equivalent } \\
\text { surface area } \\
\left(\mathrm{cm}^{2}\right)\end{array}$ & $\begin{array}{l}\text { Theoretical } \\
\text { average pore } \\
\text { radius }(\mu \mathrm{m})\end{array}$ & $\begin{array}{c}\text { Theoretical } \\
\text { single fibre } \\
\text { surface area } \\
\left(\mathrm{cm}^{2}\right)\end{array}$ \\
\hline \multirow{3}{*}{$\begin{array}{l}\text { Ferricyanide } \\
\text { (aqueous) }\end{array}$} & 1 & $26-38$ & $47-51$ & 20.4 & 58.9 \\
\hline & 2 & $24-42$ & $52-56$ & 20.4 & 59.8 \\
\hline & 3 & $24-42$ & $51-64$ & 19.9 & 61.4 \\
\hline \multirow{3}{*}{$\begin{array}{l}\text { Ferrocyanide } \\
\text { (aqueous) }\end{array}$} & 1 & $25-30$ & $57-61$ & 20.7 & 57.5 \\
\hline & 2 & $26-29$ & $59-56$ & 21.3 & 54.9 \\
\hline & 3 & $27-30$ & $57-61$ & 20.7 & 57.6 \\
\hline \multirow{3}{*}{$\begin{array}{l}\text { Vanadium(V) } \\
\text { (aqueous) }\end{array}$} & 1 & $12-34$ & $44-68$ & 20.9 & 56.7 \\
\hline & 2 & $21-39$ & $43-53$ & 19.9 & 61.7 \\
\hline & 3 & $30-40$ & $38-46$ & 22.2 & 51.4 \\
\hline \multirow{3}{*}{$\begin{array}{l}\text { Ferrocene } \\
\text { (non- } \\
\text { aqueous) }\end{array}$} & 1 & $24-47$ & $48-64$ & 22.3 & 48.3 \\
\hline & 2 & $22-40$ & $40-50$ & 22.0 & 51.9 \\
\hline & 3 & $24-43$ & $40-55$ & 22.1 & 51.7 \\
\hline
\end{tabular}


Table 3

\begin{tabular}{|c|c|}
\hline Redox System & Average Specific Capacitance $\left(\boldsymbol{\mu} \mathbf{F ~} \mathbf{c m}^{-2}\right)$ \\
\hline Ferricyanide (aqueous) & 20 \\
\hline Ferrocyanide (aqueous) & 4.2 \\
\hline Vanadium(V) (aqueous) & 14 \\
\hline Ferrocene (non-aqueous) & 7.8 \\
\hline
\end{tabular}

